\title{
Адсорбция стронция на модифицированных слоистых алюмосиликатах
}

\author{
Юрченко В.В. ${ }^{1}$, Свиридов А.В. ${ }^{1}$, Свиридов В.В ${ }^{1}$, \\ Никифоров А.Ф. ${ }^{2}$, Пряничников С.B ${ }^{3}$ \\ ${ }^{1}$ ФБГОУ ВПО «Уральский государственный лесотехнический университет», Екатеринбург \\ ${ }^{2}$ ФГАОУ ВПО «УрФУ имени первого Президента России Б.Н.Ельиина» », Екатеринбург \\ ${ }^{3}$ Федеральное государственное бюджетное учреждение науки Институт металлургии Уральского \\ отделения РАН», Екатеринбург
}

Поступила в редакцию 18.08.2016 г.

Установлена высокая эффективность адсорбции ионов стронция на интеркалированном монтмориллоните. Определены значения предельной адсорбции и термодинамические параметры адсорбции. Выявлены оптимальные условия адсорбционного извлечения ионов стронция из водных растворов. Предположительно высокие эффекты адсорбции связаны с самопроизвольным расширением и сжатием слоистой структуры монтмориллонита.

Ключевые слова: интеркаляция, интеркалированый монтмориллонит, слоистые структуры, термодинамика процесса адсорбции, энтальпия, энтропия, энергия Гиббса.

\section{Sorption of strontium in the modified layered aluminosilicates}

\author{
Yurchenko V.V. ${ }^{1}$, Sviridov A.V. ${ }^{1}$, Sviridov V.V. ${ }^{1}$, \\ Nikiforov A.A. ${ }^{2}$, Pryanichnikov S.V. ${ }^{3}$ \\ ${ }^{I}$ Ural State Forest Engineering University, Ekaterinburg \\ ${ }^{2}$ Ural Federal University, Ekaterinburg \\ ${ }^{3}$ Institute of Metallurgy, Urals Division of Russian Academy of Sciences, Ekaterinburg
}

The process of adsorption of strontium ions on the modified layered aluminosilicate - montmorillonite was studied in the paper. The thermodynamic parameters of the adsorption were calculated. The investigations were carried out on the model solutions of stable strontium.

By modifying montmorillonite surface it was established a significant increase of its adsorption capacity. The parameters of the Gibbs energy such as $\Delta \mathrm{G}, \Delta \mathrm{H}, \mathrm{T} \times \Delta \mathrm{S}$ were determined. Received and investigated adsorbents can be used for the deactivation of water containing radionuclides $\mathrm{Sr}^{90}$.

Keywords: thermodynamics of the adsorption process, the modified montmorillonite, colloidal sorbents, surface modification, enthalpy, entropy, Gibbs energy.

\section{Введение}

Сорбционные методы нашли широкое применение для очистки жидких радиоактивных растворов. В качестве сорбентов в настоящее время используют: ионообменные смолы, искусственные неорганические сорбенты, природные органические и неорганические сорбенты. 
Наименее изучены адсорбционные свойства неорганических природных сорбентов, в частности дисперсных кремнеземов, слоистых и слоисто-ленточных силикатов. Особый интерес представляют слоистые алюмосиликаты с развитой удельной поверхностью (в коллоидном состоянии).

Ранее $[1,2]$ было установлено, что высокими адсорбционными свойствами обладают интеркалированные природные бентониты по отношению к ионам тяжелых и цветных металлов $(\mathrm{Cu}, \mathrm{Ni}, \mathrm{Zn}, \mathrm{Fe})$. По нашему мнению, это связано в первую очередь с особенностями структуры бентонитовых глин, подверженной самопроизовольным деформациям в процессах адсорбции. В наибольшей степени указанные особенности проявляются для одной из разновидностей бентонитовых глин - монтмориллонита (ММ).

Интеркалляция может осуществляться различными прекурсорами органической и неорганической природы. Прекурсоры закрепляются в межслоевом пространстве сорбента, изменяя его свойства (адсорбционные, электроповерхностные). Эти свойства сохраняются в коллоидно-дисперсном состоянии.

Исходя из изложенного, значительный интерес представляло изучение адсорбционных свойств интеркалированных ММ по отношению к долгоживущим радионуклидам (в частности, стронция).

\section{Эксперимент}

В работе были использованы природные бентонитовые глины Черкасского и Зыряновского месторождений. На первом этапе интеркалляционного синтеза гели бентонитовых глин обрабатывались растворами кальцинированной соды, в результате ионы кальция в межслоевом пространстве заменялись на ионы натрия.

На втором этапе модификации ММ в Na-форме осуществляли интеркаляционное внедрение в межслоевое пространство прекурсоров - фосфатов, диэтилфосфатов. Процесс вели при непрерывном перемешивании в течение 30 мин до получения однородной массы. При промывке ММ водой прекурсор в водной фазе отсутствовал, что свидетельствовало о его прочном закреплении в фазе сорбента. Состав интеркаллированного фосфатного ММ представлен в таблице 1.

Таблица 1. Интеркаллированный фосфатами ММ

\begin{tabular}{|c|c|c|}
\hline Элементный состав & Массовая доля, $\%$ & Погрешность, $\%$ \\
\hline $\mathrm{P}_{2} \mathrm{O}_{5}$ & 29.75 & 0.29 \\
\hline $\mathrm{SiO}_{2}$ & 27.45 & 0.31 \\
\hline $\mathrm{Na}_{2} \mathrm{O}$ & 20.37 & 1.13 \\
\hline $\mathrm{Al}_{2} \mathrm{O}_{3}$ & 0.68 \\
\hline $\mathrm{Fe}_{2} \mathrm{O}_{3}$ & 13.26 & 0.12 \\
\hline $\mathrm{TiO}_{2}$ & 6.66 & 0.04 \\
\hline $\mathrm{CaO}$ & 0.762 & 0.03 \\
\hline $\mathrm{K}_{2} \mathrm{O}$ & 0.674 & 0.03 \\
\hline $\mathrm{MnO}$ & 0.616 & 0.01 \\
\hline $\mathrm{ZrO}_{2}$ & 0.057 & 0.00 \\
\hline $\mathrm{SrO}_{\mathrm{Rb}} \mathrm{O}$ & 0.0401 & 0.001 \\
\hline & 0.0191 & 0.001 \\
\hline
\end{tabular}

Закономерности адсорбции изучали на модельных растворах стабильного стронция в диапазоне концентраций от 5 до 600 ммоль/дм ${ }^{3}$ при pH 8.0-11.0. В раствор вводили сорбент в количестве 100 мг/дм ${ }^{3}$ при интенсивном перемешивании в течение 5 мин для равномерного распределения частиц сорбента в объеме раствора. 
Далее осуществляли медленное перемешивание в течение 30 минут. Этого времени было достаточно для установления адсорбционного равновесия. Остаточное содержание ионов металлов в растворе определяли после отделения твердой фазы центрифугированием атомно-адсорбционным методом на спектрофотометре с пламенной атомизацией АAC-6650 Shimadzu.

Наряду с адсорбционными свойствами сорбентов изучались их физикохимические (электроповерхностные и структурно-механические) свойства. Электроповерхностные свойства оценивали по скорости движения частиц сорбентов под действием внешнего постоянного электрического поля в электрофоретической ячей-

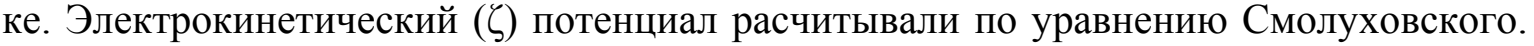
Изменение структуры сорбента оценивалось с помощью дифракционных картин, полученных на рентгеновском дифрактометре Shimadzu XRD 7000, Cu-Ko с графитовым монохроматором.

\section{Обсуждение результатов}

Интеркаляция природного ММ неорганическими прекурсорами приводила к изменению его физико-химических свойств. Так, при использовании в качестве прекурсора тринатрийфосфата, возрастал отрицательный электрокинетический потенциал частиц интеркаллированного ММ (рис. 1). Это связано с внедрением в структуру сорбента анионов прекурсора. Увеличение отрицательного значения $\zeta$-потенцала особенно сильно проявляется в области рН 6.00-10.00, что обусловлено формой нахождения прекурсора в растворе (возрастает доля ионов $\mathrm{PO}_{4}{ }^{3-}$ по сравнению с количеством ионов $\left.\mathrm{HPO}_{4}{ }^{2-}, \mathrm{H}_{2} \mathrm{PO}_{4}{ }^{-}\right)$.

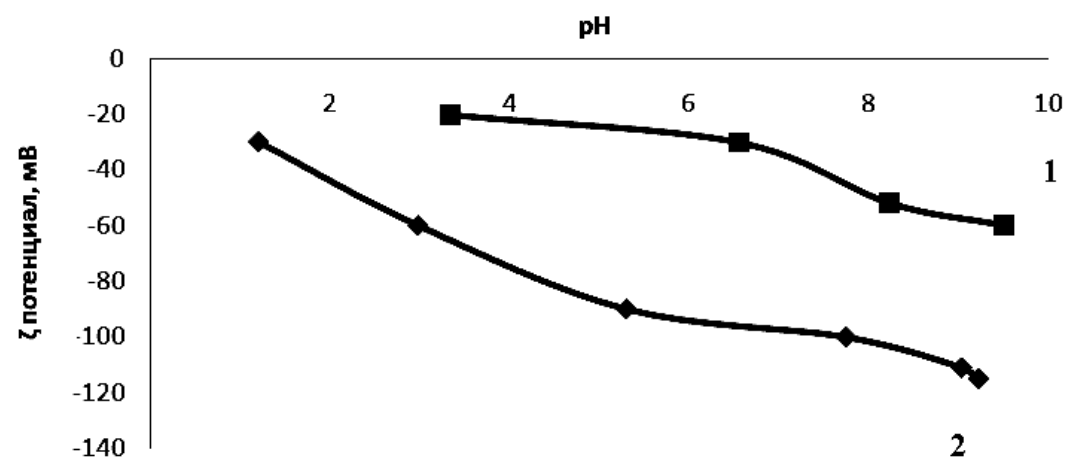

Рис. 1. Зависимость величины электрокинетического потенциала ММ от величины pH 1 - природный ММ, 2 - интерколлированный ММ

Увеличение отрицательного заряда поверхности слоев ММ приводит к их электростатическому отталкиванию. Это подтверждается рентгенографическими исследованиями. На рис. 2 представлены дифракционные картины природного и модифицированного ММ в присутствии и отсутствии воды.

Кривые описывают интенсивность дифракционного сигнала воды, сухого ММ и модифицированных образцов ММ. Видно, что при введении в структуру ММ воды и прекурсоров (картины 2, 3) существенно уменьшается относительная интенсивность пиков ММ (картина 1) и не происходит их уширения. Это связано с разупорядочиванием большей части ММ в воде на частицы, не дающие брэгговских рефлексов (не обладающие кристаллической решёткой). Если бы разупорядочивание приводило к образованию частиц ММ большего размера, то это привело бы к уширению линий пиков. Сравнение этих результатов с ранее полученными [4], позволяет допустить возможность увеличения межслоевого пространства от 0.8-1.5 нм до ح5 нм. 


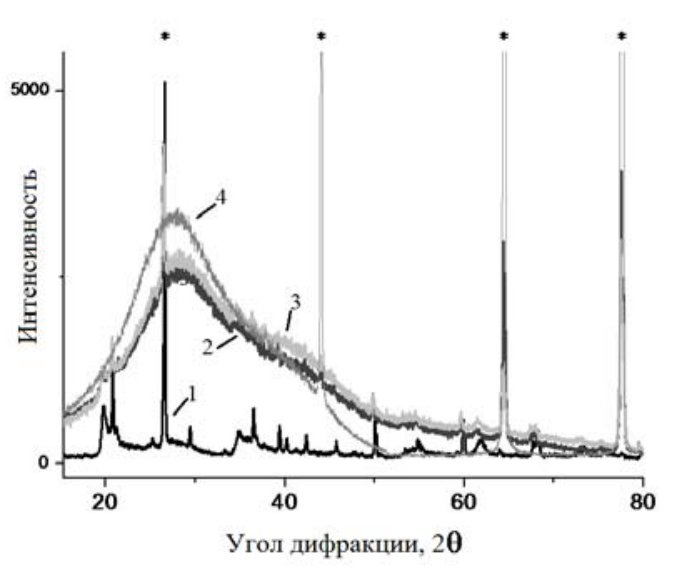

Рис. 2. Дифракционные картины: 1 - сухой ММ, 2 - интеркалированный ММ (2.5\% прекурсора), 3 - интеркалированный ММ (5\% прекурсора), 4 - вода

* обозначены пики оксида алюминия подложки, которая просвечивала сквозь исследуемый состав.

Последующие эксперименты показали, что выявленные изменения физикохимических свойств ММ сказываются на эффективности адсорбции ионов металлов на поверхности сорбента. Из рис. 3 видно, что с увеличением значений $\mathrm{pH}$ адсорбция ионов $\mathrm{Sr}^{2+}$ значительно возрастает. Это связано с изменением свойств как адсорбата, так и адсорбента. С одной стороны, ионы $\mathrm{Sr}^{2+}$ начинают переходить в менее растворимую форму $\mathrm{SrOH}^{+}$. С другой стороны, растет отрицательный заряд поверхности адсорбента, что в конечном итоге приводит к увеличению интенсивности адсорбционного взаимодействия твердой фазы с катионами $\mathrm{Sr}^{2+}$.

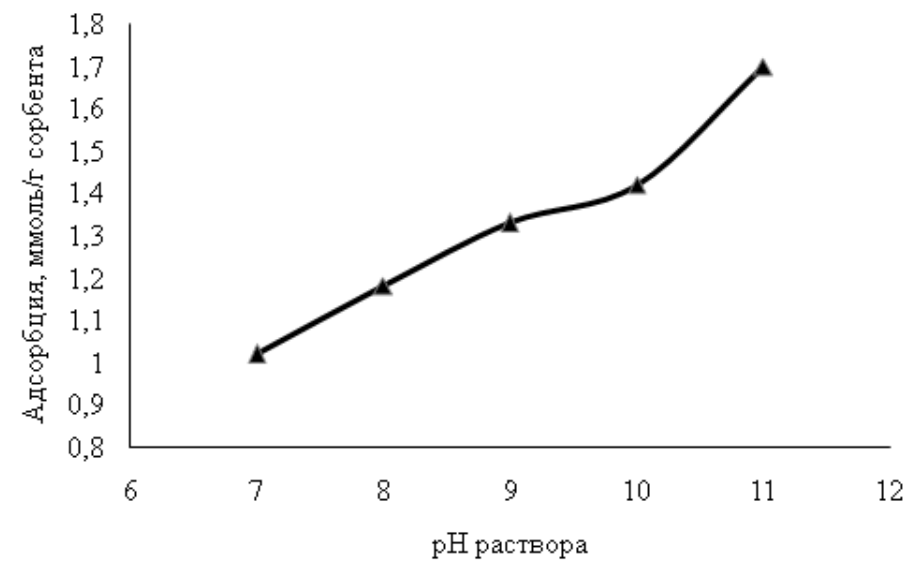

Рис. 3. Зависимость максимальной адсорбции модифицированного ММ от $\mathrm{pH}$ раствора

В ходе проведенных экспериментов были получены изотермы адсорбции ионов стронция на природном и модифицированном тринатрийфосфатом ММ (рис. 4-7).Было установлено, что изотермы адсорбции удовлетворительно описываются уравнением адсорбции Ленгмюра. Определяли предельную адсорбцию и константу адсорбционного равновесия из изотерм адсорбции при различных температурах по линеализированному уравнению Ленгмюра:

$$
\frac{C}{\Gamma}=\frac{C}{\Gamma \infty}+\frac{1}{\Gamma \infty K}
$$

где $Г$ - величина адсорбции, ммоль/г; Гळ - величина предельной адсорбции, ммоль/г; К - константа адсорбционного равновесия, дм ${ }^{3} /$ мг; $\mathrm{C}$ - равновесная концентрация ионов металлов в объеме, ммоль/дм³ . 


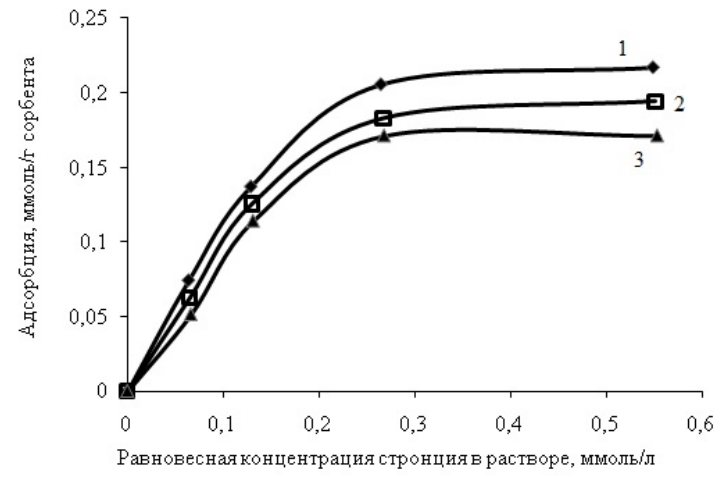

Рис. 4. Изотермы адсорбции стронция на природном ММ в диапазоне температур 293-318 К при $\mathrm{pH}=10$



Рис. 6. Изотермы адсорбции стронция на интеркалированном ММ в диапазоне температур 293-318 К при $\mathrm{pH}=10$

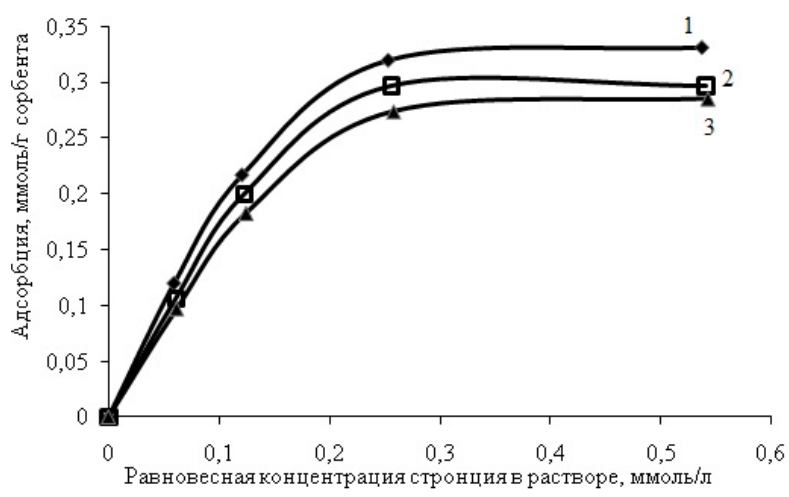

Рис. 5. Изотермы адсорбции стронция на природном ММ в диапазоне температур 293-318 К при $\mathrm{pH}=11$

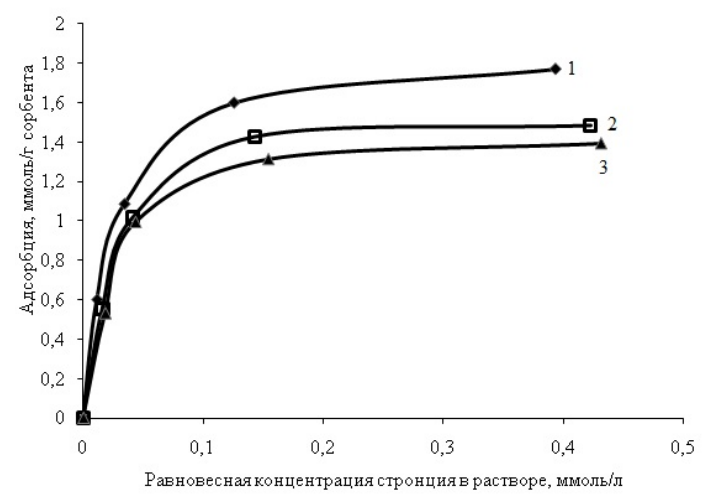

Рис. 7. Изотермы адсорбции стронция на интеркалированном ММ в диапазоне температур 293-318 К при $\mathrm{pH}=11$.

Для расчета термодинамических характеристик адсорбции $(\Delta \mathrm{G}, \Delta \mathrm{H}$ и $\Delta \mathrm{S})$ использовали уравнения изотермы и изобары в интегральном виде, исходя из предположения, что $\Delta \mathrm{H}$ в указанном узком интервале температур не зависит от температуры:

$$
\Delta G=-R T \ln K, \ln K=-\frac{\Delta H_{T}}{R T}+\text { const }
$$

По рассчитанным значениям $\Delta \mathrm{G}$ и $\Delta \mathrm{H}$ определяли значения $\Delta \mathrm{S}$ из уравнения:

$$
\Delta G=\Delta H-T \Delta S \text {. }
$$

Рассчитанные термодинамические параметры процессов сорбции ионов стронция на природном и модифицированном ММ представлены в таблице 2 и 3.

Таблица 2. Термодинамические параметры адсорбции $\mathrm{Sr}$ на МM при pH=10.

\begin{tabular}{|c|c|c|c|c|c|c|}
\hline $\begin{array}{c}\text { Термодинамический } \\
\text { параметр }\end{array}$ & \multicolumn{3}{|c|}{ Природный ММ } & \multicolumn{3}{c|}{ Интеркалированный ММ } \\
\hline Температура, $\mathrm{K}$ & 293 & 308 & 318 & 293 & 308 & 318 \\
\hline Гмах, ммоль/г & 0.22 & 0.19 & 0,17 & 1.42 & 1.38 & 1.33 \\
\hline$\Delta \mathrm{G}$, кДж/моль & -21.5 & -22.4 & -22.9 & -26.1 & -27.3 & -28.0 \\
\hline$\Delta \mathrm{H}$, кДж/моль & \multicolumn{3}{|c|}{-4.3} & & -3.8 & \\
\hline $\mathrm{T} \Delta \mathrm{S}$, кДж/моль & 17.2 & 18.1 & 18.6 & 22.3 & 23.5 & 24.2 \\
\hline
\end{tabular}


Таблица 3. Термодинамические параметры адсорбции $\mathrm{Sr}$ на ММ при $\mathrm{pH}=11$.

\begin{tabular}{|c|c|c|c|c|c|c|}
\hline $\begin{array}{c}\text { Термодинамический } \\
\text { параметр }\end{array}$ & \multicolumn{3}{|c|}{ Природный ММ } & \multicolumn{3}{|c|}{ Интеркалированный ММ } \\
\hline Температура, $\mathrm{K}$ & 293 & 308 & 318 & 293 & 308 & 318 \\
\hline Гмах, ммоль/г & 0.34 & 0.30 & 0.28 & 1.7 & 1.5 & 1.4 \\
\hline$\Delta \mathrm{G}$, кДж/моль & -22.1 & -23.2 & -23.5 & -25.6 & -27.3 & -27.9 \\
\hline$\Delta \mathrm{H}$, кДж/моль & \multicolumn{3}{|c|}{-4.6} & & -1.3 & \\
\hline $\mathrm{T} \Delta \mathrm{S}$, кДж/моль & 17.5 & 18.4 & 19.0 & 24.6 & 25.8 & 26.7 \\
\hline
\end{tabular}

Анализ термодинамических параметров приводит к следующим выводам. Для всех изотерм адсорбции энергетическая составляющая адсорбции $\Delta H$ имеет отрицательные значения, характерные для экзотермического процесса. Значения $\Delta \mathrm{H}$ составляют -4.3 кДж/моль и -3.8 кДж/моль при $\mathrm{pH}=10$, а при $\mathrm{pH}=11 \Delta \mathrm{H}$ составляют -4.6 кДж/моль и -1.3 кДж/моль для природного ММ и для интеркалированного ММ соответственно. Невысокие значения тепловых эффектов $\Delta$ Н свидетельствуют о физической адсорбции ионов стронция на ММ.

Вместе с тем, при анализе структурной (энтропийной) составляющей адсорбции обнаружены специфические особенности её поведения. Необычность изменения структурной составляющей на коллоидных слоистых сорбентах связана во всех случаях с её положительными значениями $(\mathrm{T} \Delta \mathrm{S}>0)$. Такие изменения могут быть обусловлены подвижностью поверхностных слоев адсорбента и дегидратацией ионов адсорбтива в межслоевом пространстве. Такие закономерности согласуется с ранее полученными результатами исследований для ионов $\mathrm{Cu}$ и $\mathrm{Ni}$ [1].

Предельная адсорбция стронция на сорбентах, подвергнутых интеркаляции, достигает 1.32-1.7 ммоль/г, в то время как для природного ММ - 0.17...0.34 ммоль/г. Полученные результаты сопоставимы с виличинами предельной адсорбции двухзарядных ионов на ионообменных смолах [7].

Следует отметить, что использование ММ в качестве адсорбента $\mathrm{Sr}^{2+}$ имеет приемущества по сравнению с известными адсорбентами. Они состоят в том, что после адсорбции не требуется регенерация адсорбента, вследствие его невысокой стоимости. После коагуляции коллоидных частиц адсорбента с извлеченным радиоактивным $\mathrm{Sr}^{2+}$ образуется концентрированный осадок, готовый к остекловыванию и захоронению.

\section{Заключение}

В ходе исследования процесса адсорбции стронция на модифицированных ММ была выявлена высокая эффективность извлечения ионов металлов из водных растворов. Установлена возможность повышения сорбционной емкости природного ММ методом интеркаляции. Существенное увеличение сорбционной емкости модифицированного ММ получено за счет возрастания доли активных сорбционных центров на поверхности и в межпакетном пространстве ММ. Проведен термодинамический анализ адсорбции стронция на природном модифицированном ММ, показавший значительный вклад структурной составляющей адсорбции; определены вклады энергетической и структурной составляющих адсорбции.

\section{Список литературы}

1. Свиридов А.В., Юрченко В.В., Свиридов матографические прочессы. 2016. Т. 16. № В.В., Ганебных Е.В. // Сорбиионные и хро- 1. С. 280-288 
2. Ганебных Е.В., Свиридов А.В., Мальцев Г.И. // Химия в интересах устойчивого развития. 2015. Т. 23. № 1. С. 89-95

3. Айлер Р.К. Коллоидная химия кремнезема и силикатов. М., Госстройиздат, 1959. 285 c.

4. Тарасевич Ю.И. Природные сорбенты в процессах очистки воды. Киев, Наук. думка, $1981.208 \mathrm{c}$.

\section{References}

1. Sviridov A.V., Jurchenko V.V., Sviridov V.V., Ganebnyh E.V., Sorbtsionnye i khromatograficheskie protsessy, 2016, Vol. 16, No 1, pp. 280-288.

2. Ganebnih E.V., Sviridov A.V., Malcev G.I., Himiya $v$ interesah ustoichivogo razvitiya, 2015, Vol. 23, No 1, pp. 89-95.

3. Ailer R.K. Kolloidnaya himiya kremnezema i silikatov, M., Gosstroiizdat, 1959, 285 p.

Юрченко Владимир Васильевич - старший преподаватель кафедры ХТДБиН ФБГОУ ВПО «Уральский государственный лесотехнический университет», Екатеринбург

Свиридов Алексей Владиславович - к.т.н., доцент кафедры ХТДБиН ФБГОУ ВПО «Уральский государственный лесотехнический университет», Екатеринбург

Свиридов Владислав Владимирович д.х.н., профессор кафедры ХТДБиН ФБГОУ ВПО «Уральский государственный лесотехнический университет», Екатеринбург

Никифоров Александр Федеорович - д.х.н., профессор кафедры РХиПЭ ФГАОУ ВПО «Уральский федеральный университет имени первого Президента России Б.Н.Ельцина» , Екатеринбург

Пряничников Степан Викторович - к.т.н. научный сотрудник института металлургии УрО РАН, Екатеринбург
5. Adsorption aus wäßrigen Lösungen / Rolf Kummel; Eckhard Worch. - 1. Aufl. - Leipyig: Dt. Verl. für Grundstoffind., 1990296 p.

6. Березин И.В., Мартинек К. Основы физической химии ферментативного катализа. М. «Высшая школа». 1977. 280 с.

7. Тремийон Б. Разделение на ионообменных смолах. М. издательство «МИР». 1967 г. $218 \mathrm{c}$.

4. Tarasevich Yu.I. Prirodnie sorbenti v processah ochistki void, Kiev, Nauk. dumka, 1981, $208 \mathrm{p}$.

5. Adsorption aus wäßrigen Lösungen / Rolf Kummel; Eckhard Worch, 1. Aufl., Leipyig: Dt. Verl. für Grundstoffind., 1990, 296 p.

6. Berezin I.V., Martinek K. Osnovi fizicheskoi himii fermentativnogo kataliza, M., «Visshaya shkola», 1977, 280 p.

7. Tremiion B., Razdelenie na ionoobmennih smolah., M., izdatelstvo «MIR», 1967, 218 p.

Yurchenko Vladimir V. - Assistant of Department of Ural State Forest Engineering University, Ekaterinburg, E-mail: navijoy@inbox.ru

Sviridov Alexey V. - Assistant of Professor of Ural State Forest Engineering University, Ekaterinburg, E-mail: asv1972@mail.ru

Sviridov Alexey V. - Professor of Ural State Forest Engineering University, Ekaterinburg, Email: asv1972@mail.ru

Nikiforov Alexander F. - Professor of Ural Federal University, Ekaterinburg, E-mail: alex.f.nikiforov@mail.ru

Pryanichnikov Stepan V. - Resercher of Institute of Metallurgy, Ural Branch of the Russian Academy of Sciences, Ekaterinburg 